\title{
Çekmeye Maruz Ara Parçalı Çift Takviyeli Yapıştırma Bağlantılarında Gerilme Analizi
}

\author{
Yaşar AYAZ ${ }^{*}$, Șerif ÇiTí ${ }^{2}$, Șemsettin TEMIZ ${ }^{3}$ \\ ${ }^{1}$ İnönü Üniversitesi, İnşaat Mühendisliği Bölümü, Malatya, Türkiye \\ ${ }^{2}$ Kazım Karabekir Endüstri Meslek Lisesi, Palandöken, Erzurum, Türkiye \\ ${ }^{3}$ İnönü Üniversitesi, Makine Mühendisliği Bölümü, Malatya, Türkiye
}

\begin{abstract}
ÖZET: Havacılık ve otomotiv sanayisinde çeşitli kazalar sonucu hasara uğramış bölgelerin tamiratında hasarlı olan bölge kesilip çıkartılmakta ve kesilen bölgeye yama yapılarak onarımına gidilmektedir. Hasarlı olan bölgeye zaman zaman çift taraflı yama kullanıldığından yamalar arasında parça kalınlığı kadar boşluk oluşmaktadır. Bu çalışmada iki yama arasındaki boş olan bölgeye çıkarılan parça boyutunca bir ara parça ilave etmek suretiyle tamirine gidilmiştir. Kapak kalınlığı, bindirme uzunluğu, parça kalınlığ ve ara parça boyunun mukavemet üzerindeki etkileri incelenmiştir. Parça kalınlığı ve bindirme uzunluğu arttıkça hasar yükünün arttığı, kapak (yama) kalınlığ 1 ve ara parça boyundaki artışın hasar yükünü azalttığı görülmüştür.
\end{abstract}

Anahtar Kelimeler: Yapıştırıcılar, çift takviyeli bağlantı, sonlu elemanlar analizi, mekanik özellikler, gerilme analizi

\section{Stress analysis of Double-Strap Adhesive Joint with Attachment Part Subjected to Tensile Load}

\begin{abstract}
In aerospace and automotive industries in repair of damaged parts as a result of various accidents damaged part is cut and extracted from main part and patch parts are bonded to the outer surfaces. Sometimes doublestrap patches are used and a gap remain between patches as much as thickness of patch. In this study, repairment is made by adding an attachment part extracted particle size to the empty region between the two patches. Effects of patch thichkness, overlap length, adherend thickness and attachment part length on strength are examined. It is observed that, failure load increases with increase in adherend thickness and overlap length and increase in patch thickness and attachment part decreases failure load.
\end{abstract}

Keywords: Adhesives, double-strap joints, finite element analysis, mechanical properties, stress analysis

\section{GIRIŞ}

Endüstride özellikle havacılık alanında meydana gelen kazalar oldukça yaygındır. özellikle uçakların kalkışı ve inişi esnasında meydana gelen kazalar yada uçuş esnasında uçak gövde, kanat ve özellikle kokpit bölgesinin dolu, kuş sürüsü gibi sert cisimlerle çarpışması sonucu çöküntü, çatlak, yırtılmasına sebep olmaktadır. Bu yırtılmış, çatlamış veya zayıflamış olan hasarlı bölgenin hassas bir şekilde onarılması gerekmektedir. Yırtık ve çatlak ilerlemesinin durdurulması veya zayıf olan bölgenin onarılması için çeşitli çalışmalar yapılmış ve yapılmaya devam etmektedir.

Marques and da Silva çift takviyeli yapıştırma bağlantısında parçalarının uç kısımlarda meydana gelen gerilmeleri düşürmek için yama iç kısmına ve yapıştırıcı uç kısımlarına belirli açılar vererek ve farklı yapıştırıcılar kullanarak elde ettikleri numuneleri (Şekil 1) deneysel ve numerik olarak incelemişlerdir. İnceltme açısı 45 derece olduğunda yama uçlarında gerilmelerin azaldığını, uçları inceltilmiş yamaların sert yapış̧ırııılar için daha uygun olduğunu, ikili yapıştırıcının beraber kullanılmasının gerilmeleri önemli oranda düşürdüğünü tespit etmişlerdir[1].

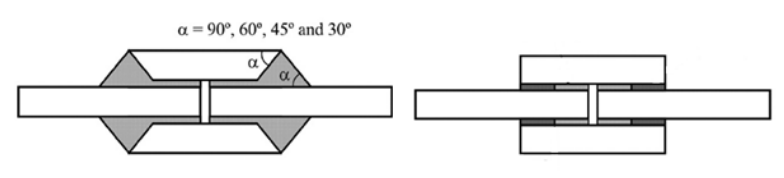

Şekil 1. Farklı çift takviyeli yapıştırma bağlantı konfigürasyonları

Temiz AA2024-T3 alüminyum levhaları çift takviyeli birleştirme yöntemi ile yapıştırarak dört nokta eğme yüklemesine maruz sonlu eleman analizini yapmıştır. Bağlantının bindirme uçlarında oluşan gerilme yığılmalarını düşürmek için farklı yapıştırma konfigürasyonunu denemiş ve bağlantının uçlarına fazla şekil değiştiren esnek yapışıtırıcı ve bağlantı ortalarına da sert yapıştırıcı konularak elde edilen bağlantının tek tip yapıştırıcı ile yapılan bağlantıya göre yaklaşık \%50

*Sorumlu Yazar: Yaşar AYAZ, yasar.ayaz@inonu.edu.tr 
civarında fazla yük taşıdığını tespit etmiştir[2]. Benzer bir çalışma Pires vd. tarafından da gerçekleştirilmiştir[3].

Fawzia vd. inşaat ve köprü yapılarında çelik malzemeleri güçlendirmek için levhalar üzerine CFRP kompozit malzemesi kaplayarak (Şekil 2) çelik plakaları çift takviyeli olarak yapıştırmışlardır ve elde ettikleri bu bağlantılarla deneysel ve nümerik olarak çalışmışlardır. Deneysel ve sonlu elemanlar analizinden elde edilen sonuçlarda bindirme uzunluklarını arttırdıkça taşınan hasar yükünün arttığını tespit etmişlerdir[4].

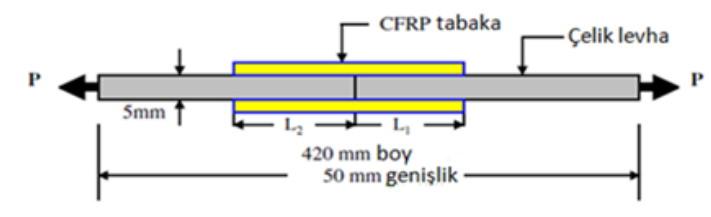

Şekil 2. Numunenin taslak görüntüsü

Özellikle uçak ve otomotiv sektöründe gerek parçaların birleştirilmesinde gerekse hasara uğramış parçaların tamirinde kullanılan klasik çift takviyeli yapıştırma bağlantısında takviye kapakları, özellikle hava ile temasın olduğu bölgelerde parça yüzeyine yapıştırılmasından dolayı, parça yüzeyinden akan hava akışına direnç göstermektedir. Çitil vd. yapmış oldukları çalışmada bu ve başka tür yapıştırma işlemi diğer konstrüktif ve estetik zorunluluklar nedeniyle, yapıştırma işlemini klasik çift takviyeli bağlantılar yerine takviye kapaklarının parça içine gömerek gerçekleştirmişler ve bu durumda oluşan gerilme dağılımı ve taşınacak hasar yükü üzerindeki etkisi araştırmışlardır[5].

\section{MATERYAL ve YÖNTEM}

$\mathrm{Bu}$ çalışmada tamir amaçlı yapıştırma bağlantısında oluşan gerilme analizi sonlu eleman yöntemi kullanılarak yapılmıştır. Aynı zamanda sonlu eleman yönteminde kullanılan modelin doğrulanması amacıyla, doğrulama deneyleri yapılmıştır.

Çalışma kapsamında, $\mathrm{h}=4.35,5$ ve $6 \mathrm{~mm}$ kalınlığında, $100 \mathrm{~mm}$ sabit boy ve $25 \mathrm{~mm}$ sabit en için alüminyum alaşım (AA 2024-T3) levhalar kullanıldı. Ara elemanlar $\mathrm{h}=4.35,5$ ve $6 \mathrm{~mm}$ kalınlığında, $\mathrm{L} 1=10,15$, $20 \mathrm{~mm}$ bindirme uzunluğunda ve $25 \mathrm{~mm}$ eninde (AA 2024-T3) levhalar kullanıldı. Yama (kapak) olarak $L=40$, 50 ve $60 \mathrm{~mm}$ bindirme uzunluklarında $\mathrm{t}=0.6,0.8$ ve $1 \mathrm{~mm}$ kalınlığında $25 \mathrm{~mm}$ eninde (Şekil 3 ve Şekil 4 ) paslanmaz çelik kullanıldı. Yapıştırtıcı olarak CYTEC $\mathrm{FM}^{\circledR} 73$ OST; $-55^{\circ} \mathrm{C}$ ile $82^{\circ} \mathrm{C}$ sicaklikları arasinda mükemmel yapısal performans sağlayan epoksi esaslı yapısal bir film yapıştırıcı kullanıldı. Yapıştırıcının kürleșebilmesi için, bağlantı numuneleri 120 dakikalık süre boyunca $0.5 \mathrm{MPa}$ basınçta ve $120^{\circ} \mathrm{C}$ sicaklıkta bekletildi. Çift takviyeli olarak yapıştırılan numunelerin üç boyutlu sonlu elamanlar yöntemiyle gerilme analizleri yapıldı. Sonlu elemanlarla oluşturulan modellerin doğrulanması için doğrulama deneyleri yapıldı.

Farklı bindirme uzunluklarındaki gerilmeler karşılaştırıldıkları zaman, yine her bindirme uzunluğu kendi uzunluğuna bölünerek diyagramın yatay ekseni 01 aralığına dönüştürülmüştür. Bütün yapıştırma bağlantıları için farklı parça kalınlıklarına eşit bir kuvvet elde etmek için farklı parça kalınlığına farklı basınç kuvveti uygulanmıştır. Basınç değerleri dik yüzey alanı ile çarpıldığında eşit kuvveti vermektedir; $4.35 \mathrm{~mm}$ parça kalınlığ için $85 \mathrm{MPa}, 5 \mathrm{~mm}$ parça kalınlığ $73.95 \mathrm{MPa}$, $6 \mathrm{~mm}$ parça kalınlığı için $61.625 \mathrm{MPa}$ yayılı yük etki edecek şekilde elde edilmiştir. Yani sonlu eleman modelinde h kalınlığına eşit kuvvet elde etmek için farklı basınç yükü yüklenirken gerilmeler elde edilmiş ve karşılaştırılmıştır. Burada $85 \mathrm{MPa}$ seçilmesinin nedeni en düşük hasar yükünü taşıyan yapıştırma bağlantısının yükü olduğu için seçilmiştir.

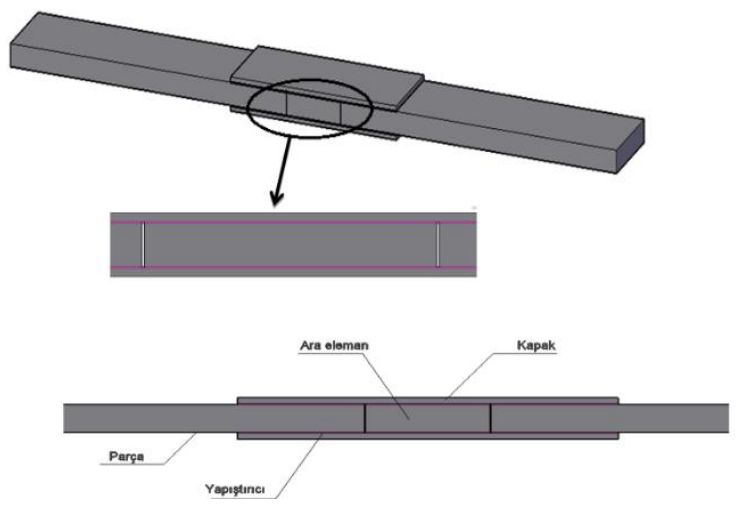

Şekil 3. Deneylerde kullanılan bağlantı elemanlarının a) katı modeli b) katı model kesit görünüşü
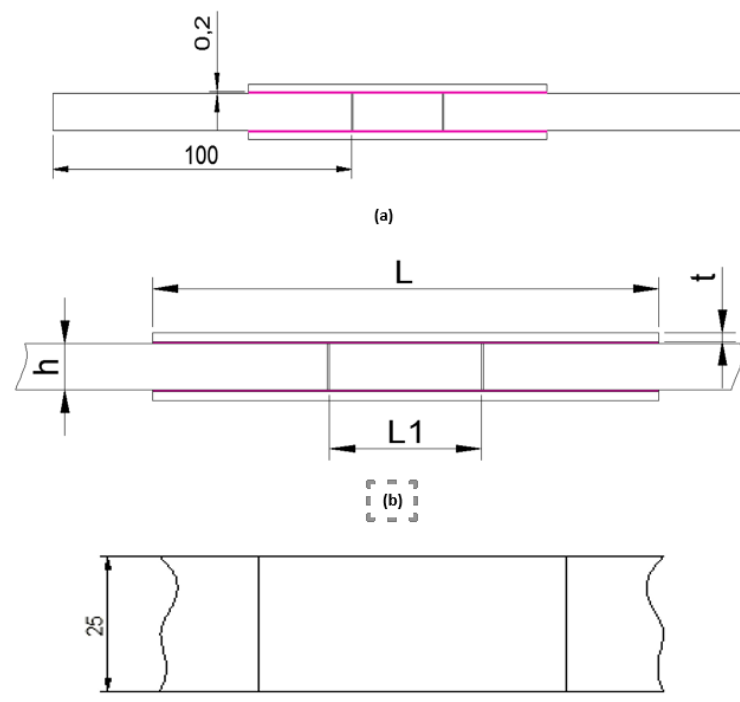

(c)

Şekil 4. Deneylerde kullanılan bağlantı elemanlarının a) ön görünüşü b) kesit görünüşü c) üst görünüşü 
Lineer olamayan sonlu eleman modelinin oluşturulmasında kullanılan kapak malzemesi gerilme şekil değiştirme diyagramını elde edilmesi için, paslanmaz çelikten ASTM370 standardına göre çekme numunesi yapılmış, test cihazında $5 \mathrm{~mm} /$ dak çekme hızında çekilmiş ve elde edilen gerçek gerilme-şekil değiştirme diyagramı Şekil 5.a'da verilmiştir. Şekil 5'de diyagramları verilen yapıştırılan malzeme ve yapıştırıcının gerilme-şekil değiştirme diyagramları Aydın vd. yaptıkları çalışmadan alınmıştır[6].

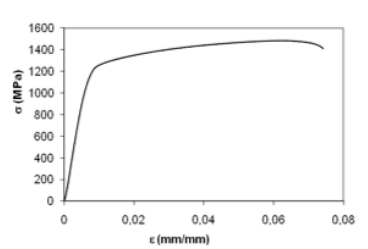

(a)

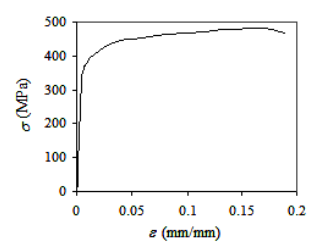

(b)

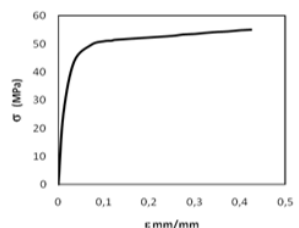

(c)

Şekil 5. FM73 yapıştırıcı, AA2024 parça ve Kapak malzemesinin gerilme şekil değiştirme diyagramları; a) Paslanmaz Çelik, b) AA2024, c) FM73

\section{ARAŞTIRMA BULGULARI ve TARTIŞMA}

\subsection{Deneysel Sonuçlar}

Sonlu eleman modelinin doğrulanması için parça kalınlığ $\mathrm{h}=4.35 \mathrm{~mm}$, kapak kalınlığ $\mathrm{t}=0.8$ ve $1 \mathrm{~mm}$ ve bindirme uzunluğu $\mathrm{L}=50 \mathrm{~mm}$ olan üçer adet numune $0.2 \mathrm{~mm}$ film kalınlığında FM 73 yapıştırıcı ile yapıştırıldı. Parça ile ara parça arasına FM73 yapıştırıcıdan etkilenmeyen $0.2 \mathrm{~mm}$ kalınlığında bant yapıştırılarak bağlantı numunesi elde edilmiş ve çekme cihazında $5 \mathrm{~mm} /$ dak çekme hızında çekilerek sonuçlar Tablo 1'de verilmiştir. Deneysel ve nümerik sonuçlar incelendiğinde sonuçların uyumlu olduğu görülmektedir. $\mathrm{Bu}$ uyum, oluşturulan sonlu eleman modelinin doğruluğunu desteklemektedir.

\subsection{Nümerik Sonuçlar}

\subsubsection{Hasar yükü sonuçları}

Sonlu elemanlarla çözümlemesinde L1 değerleri sırasıyla 10, 15, $20 \mathrm{~mm}$, parça kalınlığı h sırasıyla 4.35, 5, $6 \mathrm{~mm}$ olarak alınmıştır. Yamanın bindirme uzunluğu L değerleri sırsıyla 40, 50, $60 \mathrm{~mm}$ ve kalınlığı t sırasıyla 0.6, 0.8, 1 mm olarak alınmıştır. Parça ve kapak genişliği sabit olup $25 \mathrm{~mm}$ dir. Hasar yükü sonuçları tablo 2-3-4-5-6-7'de verilmiştir. Şekil 6'da sonlu elemanlarda kullanılan bağlantı elemanlarının iki boyutlu kesit görüntüsü verilmiştir.

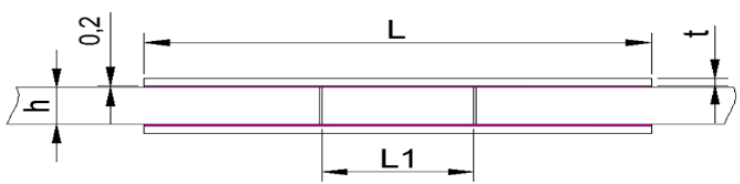

Şekil 6. sonlu elemanlarda kullanılan bağlantı elemanının iki boyutlu kesit görüntüsü

Tablo 1. $\mathrm{h}=4.35 \mathrm{~mm}$ parça kalınlığı, $\mathrm{L}=50$ bindirme uzunluğu, $\mathrm{t}=0.8$ ve $1 \mathrm{~mm}$ kapak kalınlığ ve $\mathrm{L} 1=10,15$ ve $20 \mathrm{~mm}$ ara parça boyları için deneysel ve nümerik çekme hasar yükleri

\begin{tabular}{|c|c|c|c|c|c|c|}
\hline $\begin{array}{c}\mathrm{h} \\
(\mathrm{mm})\end{array}$ & $\begin{array}{c}\mathrm{t} \\
(\mathrm{mm})\end{array}$ & $\begin{array}{c}\mathrm{L} 1 \\
(\mathrm{~mm})\end{array}$ & $\begin{array}{c}\mathrm{L} \\
(\mathrm{mm})\end{array}$ & $\begin{array}{c}\text { Deneysel Hasar } \\
\text { Yükü, PDEN }(\mathrm{N})\end{array}$ & $\begin{array}{c}\text { (Nümerik) Hasar } \\
\text { Yükü, PSEY }(\mathrm{N})\end{array}$ & P SEY $_{\text {S PEN }}$ \\
\hline 4.35 & 0.8 & 10 & 50 & 26405 & 27731 & 0.97 \\
\hline 4.35 & 1 & 10 & 50 & 22536 & 27351 & 0.92 \\
\hline 4.35 & 0.8 & 15 & 50 & 24321 & 24469 & 0.99 \\
\hline 4.35 & 0.8 & 20 & 50 & 21892 & 21098 & 0.96 \\
\hline
\end{tabular}


Tablo 2. $\mathrm{h}=4.35 \mathrm{~mm}$ parça kalınlığ $1, \mathrm{~L}=40,50$ bindirme uzunluğu, $\mathrm{t}=0.6,0.8$ ve $1 \mathrm{~mm}$ kapak kalınlığ 1 ve $\mathrm{L} 1=10$, 15 ve $20 \mathrm{~mm}$ ara parça boylarındaki bağlantı numuneleri için nümerik çekme hasar yükleri

\begin{tabular}{|c|c|c|c|c|}
\hline $\mathrm{h}$ & $\mathrm{t}$ & $\mathrm{L} 1$ & $\mathrm{~L}$ & $\begin{array}{c}\text { Nümerik } \\
\text { HasarYükü }\end{array}$ \\
\hline$(\mathrm{mm})$ & $(\mathrm{mm})$ & $(\mathrm{mm})$ & $(\mathrm{mm})$ & $(\mathrm{N})$ \\
\hline 4.35 & 0.6 & 10 & 40 & 21315 \\
\hline 4.35 & 0.8 & 10 & 40 & 21315 \\
\hline 4.35 & 1 & 10 & 40 & 20880 \\
\hline 4.35 & 0.6 & 15 & 40 & 17726 \\
\hline 4.35 & 0.8 & 15 & 40 & 17563 \\
\hline 4.35 & 1 & 15 & 40 & 17454 \\
\hline 4.35 & 0.6 & 20 & 40 & 14138 \\
\hline 4.35 & 0.8 & 20 & 40 & 14029 \\
\hline 4.35 & 1 & 20 & 40 & 13920 \\
\hline 4.35 & 0.6 & 10 & 50 & 27731 \\
\hline 4.35 & 0.8 & 10 & 50 & 27731 \\
\hline 4.35 & 1 & 10 & 50 & 27351 \\
\hline 4.35 & 0.6 & 15 & 50 & 24795 \\
\hline 4.35 & 0.8 & 15 & 50 & 24469 \\
\hline 4.35 & 1 & 15 & 50 & 24197 \\
\hline 4.35 & 0.6 & 20 & 50 & 21315 \\
\hline 4.35 & 0.8 & 20 & 50 & 21098 \\
\hline 4.35 & 1 & 20 & 50 & 20880 \\
\hline
\end{tabular}

Tablo 3. $\mathrm{h}=4.35 \mathrm{~mm}$ parça kalınlığ $1, \mathrm{~L}=60$ bindirme uzunluğu, $\mathrm{t}=0.6,0.8$ ve $1 \mathrm{~mm}$ kapak kalınlığ $\mathrm{ve} \mathrm{L} 1=10$, 15 ve $20 \mathrm{~mm}$ ara parça boylarındaki bağlantı numuneleri için nümerik çekme hasar yükleri

\begin{tabular}{|c|c|c|c|c|}
\hline $\mathrm{h}$ & $\mathrm{t}$ & $\mathrm{L} 1$ & $\mathrm{~L}$ & $\begin{array}{c}\text { Nümerik } \\
\text { HasarYükü }\end{array}$ \\
\hline$(\mathrm{mm})$ & $(\mathrm{mm})$ & $(\mathrm{mm})$ & $(\mathrm{mm})$ & $(\mathrm{Mpa})$ \\
\hline 4.35 & 0.6 & 10 & 60 & 34637 \\
\hline 4.35 & 0.8 & 10 & 60 & 33767 \\
\hline 4.35 & 1 & 10 & 60 & 33006 \\
\hline 4.35 & 0.6 & 15 & 60 & 31483 \\
\hline 4.35 & 0.8 & 15 & 60 & 30831 \\
\hline 4.35 & 1 & 15 & 60 & 30341 \\
\hline 4.35 & 0.6 & 20 & 60 & 28166 \\
\hline 4.35 & 0.8 & 20 & 60 & 27731 \\
\hline 4.35 & 1 & 20 & 60 & 27405 \\
\hline
\end{tabular}

Tablo 4. $\mathrm{h}=5 \mathrm{~mm}$ parça kalınlığı, $\mathrm{L}=40,50$ bindirme uzunluğu, $\mathrm{t}=0.6,0.8$ ve $1 \mathrm{~mm}$ kapak kalınlığ 1 ve $\mathrm{L} 1=10$, 15 ve $20 \mathrm{~mm}$ ara parça boylarındaki bağlantı numuneleri için nümerik çekme hasar yükleri

\begin{tabular}{|c|c|c|c|c|}
\hline $\mathrm{h}$ & $\mathrm{t}$ & $\mathrm{L} 1$ & $\mathrm{~L}$ & $\begin{array}{c}\text { Nümerik } \\
\text { HasarYükü }\end{array}$ \\
\hline$(\mathrm{mm})$ & $(\mathrm{mm})$ & $(\mathrm{mm})$ & $(\mathrm{mm})$ & $(\mathrm{N})$ \\
\hline 5 & 0.6 & 10 & 40 & 21438 \\
\hline 5 & 0.8 & 10 & 40 & 21250 \\
\hline 5 & 1 & 10 & 40 & 21063 \\
\hline 5 & 0.6 & 15 & 40 & 18438 \\
\hline 5 & 0.8 & 15 & 40 & 17688 \\
\hline 5 & 1 & 15 & 40 & 17625 \\
\hline 5 & 0.6 & 20 & 40 & 14188 \\
\hline 5 & 0.8 & 20 & 40 & 14063 \\
\hline 5 & 0.6 & 10 & 50 & 28250 \\
\hline 5 & 0.8 & 10 & 50 & 28125 \\
\hline 5 & 1 & 10 & 50 & 27813 \\
\hline 5 & 0.6 & 15 & 50 & 24875 \\
\hline 5 & 0.8 & 15 & 50 & 24688 \\
\hline 5 & 1 & 15 & 50 & 24500 \\
\hline 5 & 0.6 & 20 & 50 & 21438 \\
\hline 5 & 0.8 & 20 & 50 & 21250 \\
\hline
\end{tabular}

Tablo 5. $\mathrm{h}=5 \mathrm{~mm}$ parça kalınlığı, $\mathrm{L}=60$ bindirme uzunluğu, $\mathrm{t}=0.6,0.8$ ve $1 \mathrm{~mm}$ kapak kalınlığ 1 ve $\mathrm{L} 1=10$, 15 ve $20 \mathrm{~mm}$ ara parça boylarındaki bağlantı numuneleri için nümerik çekme hasar yükleri

\begin{tabular}{|c|c|c|c|l|}
\hline $\mathrm{h}$ & $\mathrm{t}$ & $\mathrm{L} 1$ & $\mathrm{~L}$ & $\begin{array}{c}\text { Nümerik } \\
\text { HasarYükü }\end{array}$ \\
\hline$(\mathrm{mm})$ & $(\mathrm{mm})$ & $(\mathrm{mm})$ & $(\mathrm{mm})$ & $(\mathrm{N})$ \\
\hline 5 & 0.6 & 10 & 60 & 34750 \\
\hline 5 & 0.8 & 10 & 60 & 34563 \\
\hline 5 & 1 & 10 & 60 & 33938 \\
\hline 5 & 0.6 & 15 & 60 & 31563 \\
\hline 5 & 0.8 & 15 & 60 & 31375 \\
\hline 5 & 1 & 15 & 60 & 30938 \\
\hline 5 & 0.6 & 20 & 60 & 28250 \\
\hline 5 & 0.8 & 20 & 60 & 28125 \\
\hline 5 & 1 & 20 & 60 & 27750 \\
\hline
\end{tabular}


Tablo 6. $\mathrm{h}=6 \mathrm{~mm}$ parça kalınlığ $1, \mathrm{~L}=40,50$ bindirme uzunluğu, $\mathrm{t}=0.6,0.8$ ve $1 \mathrm{~mm}$ kapak kalınlığ 1 ve $\mathrm{L} 1=10$, 15 ve $20 \mathrm{~mm}$ ara parça boylarındaki bağlantı numuneleri için nümerik çekme hasar yükleri

\begin{tabular}{|c|c|c|c|c|}
\hline $\mathrm{h}$ & $\mathrm{t}$ & $\mathrm{L} 1$ & $\mathrm{~L}$ & $\begin{array}{c}\text { Nümerik } \\
\text { Hasar } \\
\text { Yükü }\end{array}$ \\
\hline$(\mathrm{mm})$ & $(\mathrm{mm})$ & $(\mathrm{mm})$ & $(\mathrm{mm})$ & $(\mathrm{N})$ \\
\hline 6 & 0.6 & 10 & 40 & 21525 \\
\hline 6 & 0.8 & 10 & 40 & 21375 \\
\hline 6 & 1 & 10 & 40 & 21225 \\
\hline 6 & 0.6 & 15 & 40 & 18000 \\
\hline 6 & 0.8 & 15 & 40 & 17775 \\
\hline 6 & 1 & 15 & 40 & 17700 \\
\hline 6 & 0.6 & 20 & 40 & 14100 \\
\hline 6 & 0.8 & 20 & 40 & 14100 \\
\hline 6 & 1 & 20 & 40 & 14025 \\
\hline 6 & 0.6 & 10 & 50 & 28050 \\
\hline 6 & 0.8 & 10 & 50 & 28275 \\
\hline 6 & 1 & 10 & 50 & 28200 \\
\hline 6 & 0.6 & 15 & 50 & 25125 \\
\hline 6 & 0.8 & 15 & 50 & 24975 \\
\hline 6 & 1 & 15 & 50 & 24750 \\
\hline 6 & 0.6 & 20 & 50 & 21525 \\
\hline 6 & 0.8 & 20 & 50 & 21375 \\
\hline 6 & 1 & 20 & 50 & 21225 \\
\hline
\end{tabular}

Tablo 7. $\mathrm{h}=6 \mathrm{~mm}$ parça kalınlığı, $\mathrm{L}=60$ bindirme uzunluğu, $\mathrm{t}=0.6,0.8$ ve $1 \mathrm{~mm}$ kapak kalınlığ 1 ve $\mathrm{L} 1=10$, 15 ve $20 \mathrm{~mm}$ ara parça boylarındaki bağlantı numuneleri için nümerik çekme hasar yükleri

\begin{tabular}{|c|c|c|c|c|}
\hline $\mathrm{h}$ & $\mathrm{t}$ & $\mathrm{L} 1$ & $\mathrm{~L}$ & $\begin{array}{c}\text { Nümerik } \\
\text { HasarYükü }\end{array}$ \\
\hline$(\mathrm{mm})$ & $(\mathrm{mm})$ & $(\mathrm{mm})$ & $(\mathrm{mm})$ & $(\mathrm{Mpa})$ \\
\hline 6 & 0.6 & 10 & 60 & 34125 \\
\hline 6 & 0.8 & 10 & 60 & 35250 \\
\hline 6 & 1 & 10 & 60 & 34875 \\
\hline 6 & 0.6 & 15 & 60 & 32025 \\
\hline 6 & 0.8 & 15 & 60 & 31875 \\
\hline 6 & 1 & 15 & 60 & 31575 \\
\hline 6 & 0.6 & 20 & 60 & 28725 \\
\hline 6 & 0.8 & 20 & 60 & 28425 \\
\hline 6 & 1 & 20 & 60 & 28200 \\
\hline
\end{tabular}

Tablo 2-7 incelendiğinde, yapıştırılan parça kalınlığındaki artışın hasar yükünü arttırdığı görülmektedir. ara parça boyu ve kapak kalınlıklarındaki artışların ise hasar yüklerini azalttığı görülmektedir. Bindirme uzunluğu arttıkça hasar yüklerinin arttığı görülmektedir.

\subsubsection{Gerilme Dağılımı Sonuçları}

Gerilme dağılımı sonuçları için sonlu eleman modelinin bağlantı elemanın A-B hattı ve A-C hattını belirten üç boyutlu görüntüsü ve indislerin yönleri şekil 7'de gösterildiği gibidir. Sonlu eleman analizinde, bağlantıların yama analizleri, elastik; levha malzemesi ve yapıştırıcının analizleri elasto-plastik olmak üzere, gerilme analizleri sonlu elemanlar paket programı ANSYS 12 sürümü kullanılarak yapılmıştır. Şekil 7.b'de verilen modelin analizinde 8 düğüm noktasına sahip 3D dikdörtgen prizması olan Solid185 kullanılmıştır. Gerilme dağılımları açısından kritik bölge olan yapıştırma işleminin gerçekleştirildiği bölge, daha küçük elemanlara bölünmüștür.

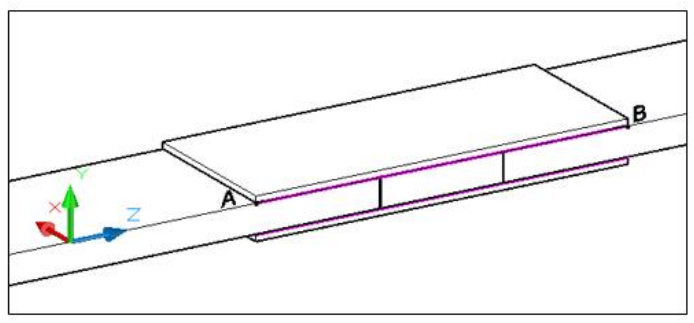

(a)

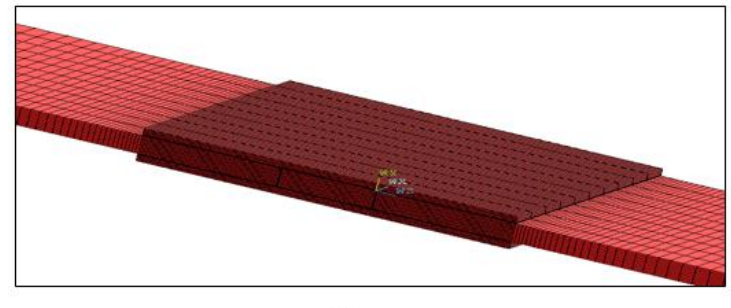

Şekil 7. Sonlu elemanlarda kullanılan bağlantı elemanının a) üç boyutlu görüntüsü b) sonlu eleman modeli

Bütün yapıştırma bağlantıları için gerilmeler kuvvetin kendisine dik yüzey alanına bölünmesiyle 85 , 73.95, 61.625 MPa yayılı yük etki edecek şekilde elde edilmiştir. Yani sonlu eleman modelinde hx25 alana 9243.75 Newton'luk kuvvet yüklenerek gerilmeler elde edilmiş ve karşılaştırılmıştır. Bu değer en düşük hasar yükünü taşıyan yapıştırma bağlantısının yükü olarak seçilmiştir. 


\subsubsection{AB hattı boyunca gerilme dağılımı sonuçları}

\subsection{Bindirme uzunluğuna bağlı olarak gerilme dağılımı sonuçları}

Farklı bindirme uzunlukları, $5 \mathrm{~mm}$ parça, 0.8 mm kapak kalınlığına ve $15 \mathrm{~mm}$ ara boyuna sahip çift takviyeli bağlantının A-B hattı boyunca normal $\left(\sigma_{\mathrm{x}}, \sigma_{\mathrm{y}}\right.$, $\sigma_{\mathrm{z}}$ ) ve von-Mises $\left(\sigma_{\text {eqv }}\right)$ eşdeğer gerilme dağılımları için Şekil 8'de verilmiştir. $\sigma_{\mathrm{x}}, \sigma_{\mathrm{y}}, \sigma_{\mathrm{z}}$ ve $\sigma_{\text {eqv }}$ gerilmeleri ara parça uçlarında en büyük değerlere ulaşmıştır. Bunun ara parça uçlarında meydana gelen süreksizlikten kaynaklandığı düşünülmektedir (Şekil 7). Kapak uçları yani A ve B noktalarında bindirme boyu arttıkça gerilme değerlerinin azaldığı görülmektedir. Bunun nedeni bindirme uzunluğu arttıkça yapıştırıcı alanı artmakta gerilmeler düşmektedir.Ara parça uçlarında ise $50 \mathrm{~mm}$ bindirme boyunda normal gerilmeler maksimum olmaktadır. Eşdeğer gerilmeler ise ara parça boyunun artması ile azalmaktadır.

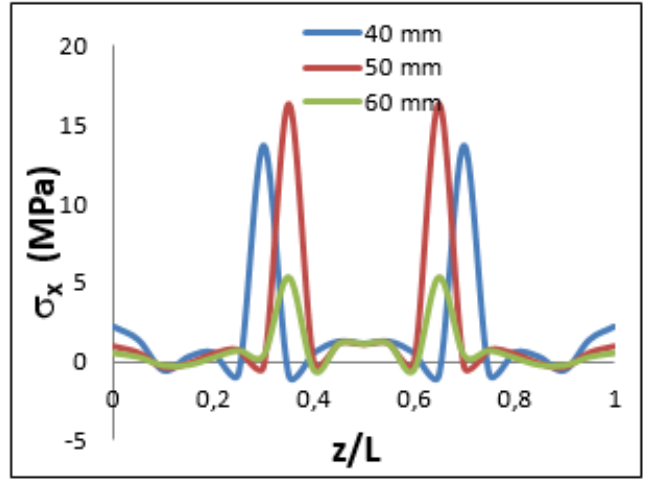

(a)

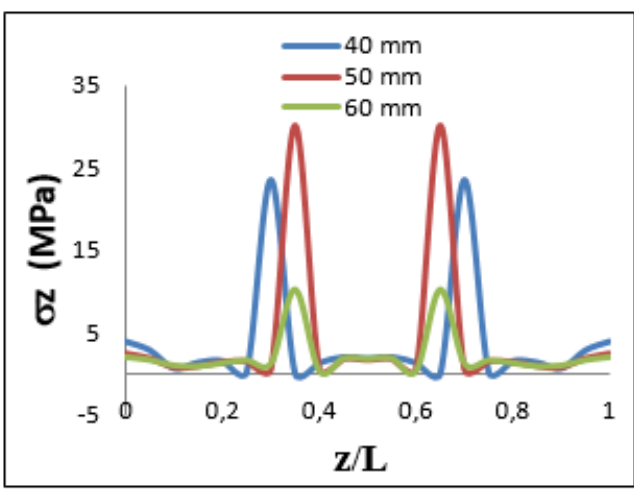

(c)
Şekil 9'da $5 \mathrm{~mm}$ parça, $0.8 \mathrm{~mm}$ kapak kalınlığına ve $15 \mathrm{~mm}$ ara parça boyuna sahip çift takviyeli bağlantının A-B hattı boyunca farklı bindirme uzunlukları için kayma gerilme dağılımları görülmektedir. $\tau_{x y}$ dağılımı bindirme uzunluğu uçlarında negatif olup bindirme uzunluğu ortalarına doğru işaret değiştirerek pozitif olmaktadır. Bindirme uzunluğunun $\tau_{\mathrm{xy}}$ dağılımı üzerine dikkate değer bir etkisi olmamaktadır.

Kapak kenarlarında $\tau_{\mathrm{yz}}$ gerilmeleri maksimum değer almakta ve bindirme uzunluğunun artması ile azalmaktadır. Ara parça uçlarında ise $50 \mathrm{~mm}$ ara parça kalınlığında daha büyük gerilme dağılımı görülmektedir. Ara parça uçlarında $\tau_{\mathrm{yz}}$ gerilmeleri işaret değiştirmektedir. $\tau_{\mathrm{yz}}$ gerilmelerinin $\tau_{\mathrm{xy}}$ kayma gerilerinden çok daha büyük değerler aldığı görülmektedir

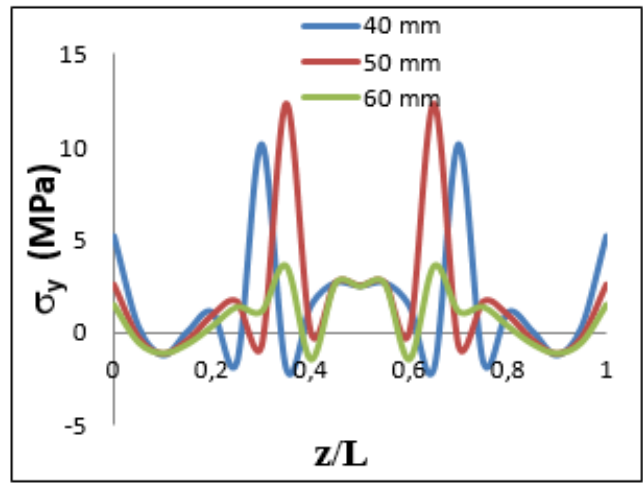

(b)

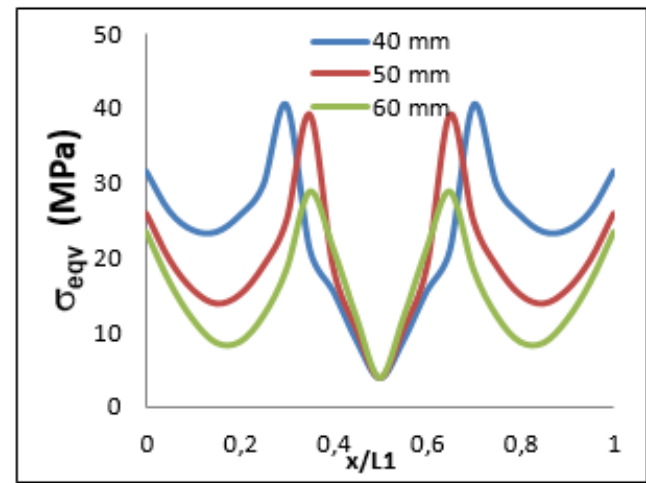

(d)

Şekil 8. $5 \mathrm{~mm}$ parça, $0.8 \mathrm{~mm}$ kapak kalınlığına ve $15 \mathrm{~mm}$ ara boyuna sahip çift takviyeli bağlantının A-B hattı boyunca farklı bindirme uzunlukları için normal ve von-Mises eşdeğer gerilme dağılımları a) $\left.\sigma_{x}, b\right) \sigma_{y}$, c) $\sigma_{z}$ d) $\sigma_{\text {eqv }}$ gerilme dağılımları 


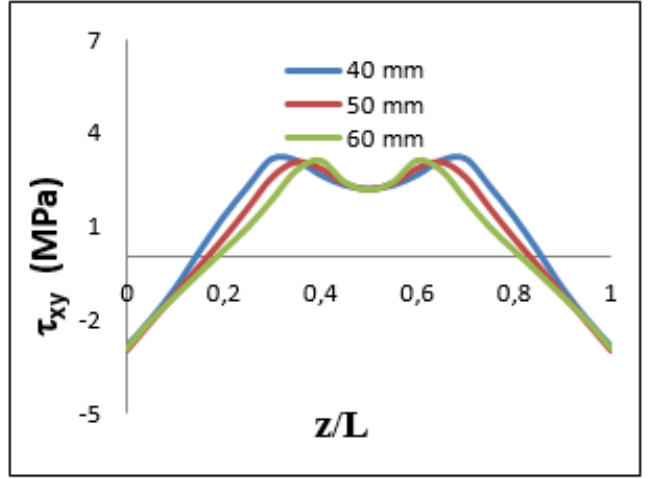

(a)

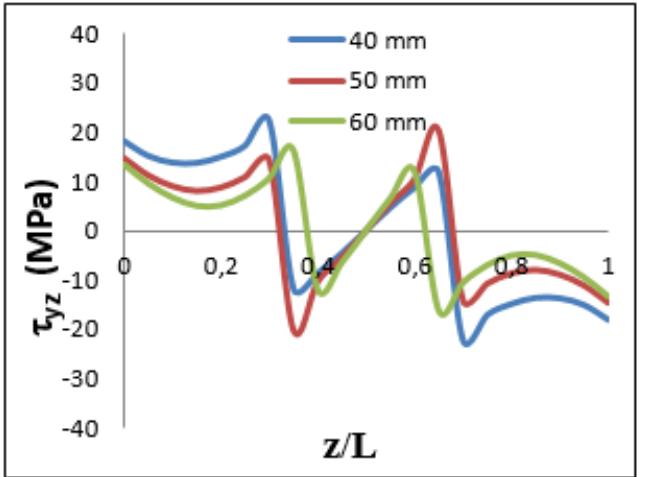

(b)

Şekil $9.5 \mathrm{~mm}$ parça, $0.8 \mathrm{~mm}$ kapak kalınlı̆̆ına ve $15 \mathrm{~mm}$ ara boyuna sahip çift takviyeli bağlantının A-B hattı boyunca farklı bindirme uzunlukları için kayma gerilme dağılımları a) $\tau_{\mathrm{xy}}$, b) $\tau_{\mathrm{yz}}$

\subsection{Ara boya bağlı olarak gerilme dağılımı sonuçları}

$5 \mathrm{~mm}$ parça, $0.8 \mathrm{~mm}$ kapak kalınlığ 1 ve $50 \mathrm{~mm}$ bindirme uzunluğuna sahip çift takviyeli bağlantının AB hattı boyunca normal gerilmeleri Şekil 10'da verilmiştir. Normal gerilmelerin ara parça uçlarında maksimum değere ulaştığı, diğer kısımlarda ise çok küçük olduğu görülmektedir. Ara parça uzunluğunun ise normal gerilmeler üzerinde önemli bir etkisi olmadığı görülmektedir.
Şekil 11'de ise $\tau_{x y}$ ve $\tau_{y z}$ kayma gerilmeleri görülmektedir. $\tau_{x y}$ kayma gerilmeleri kapak uçlarında negatif iken ara parça üzerinde pozitif değer almakta ve artmaktadır. $\tau_{\mathrm{yz}}$ gerilmeleri $\tau_{\mathrm{xy}}$ gerilmelerinden çok daha büyük değerler almaktadır. $\tau_{\mathrm{yz}}$ gerilmeleri ara parça uçlarında maksimum değerlere ulaşmaktadır. 


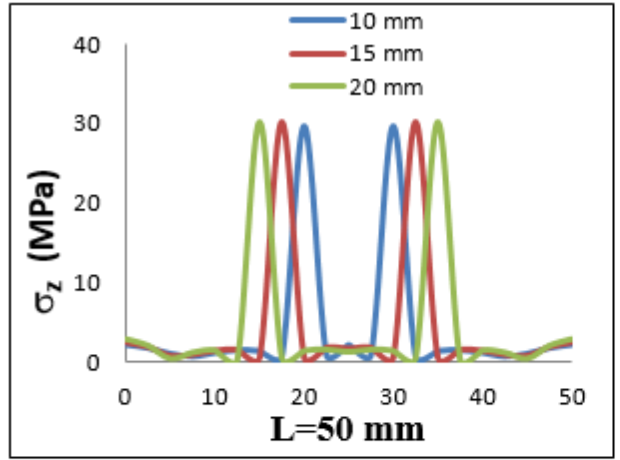

(a)

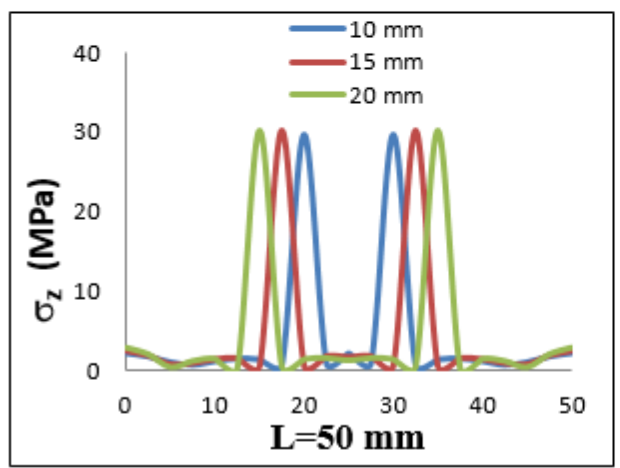

(c)

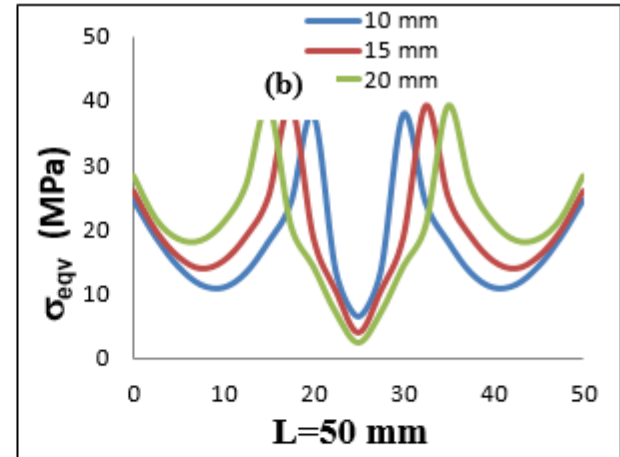

(b)

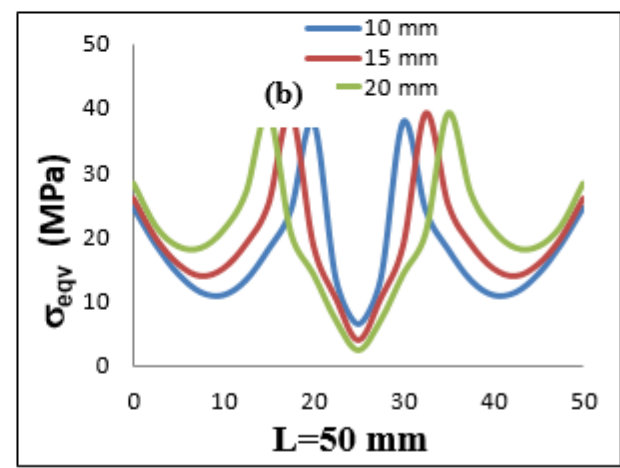

(d)

Şekil 10. $5 \mathrm{~mm}$ parça, $0.8 \mathrm{~mm}$ kapak kalınlığına ve $50 \mathrm{~mm}$ bindirme uzunluğuna sahip çift takviyeli bağlantının A-B hattı boyunca farklı ara parça boyları için normal ve eşdeğer gerilme dağılımları a) $\left.\sigma_{x}, b\right) \sigma_{y}$, c) $\sigma_{z}$ d) $\sigma_{\text {eqv }}$

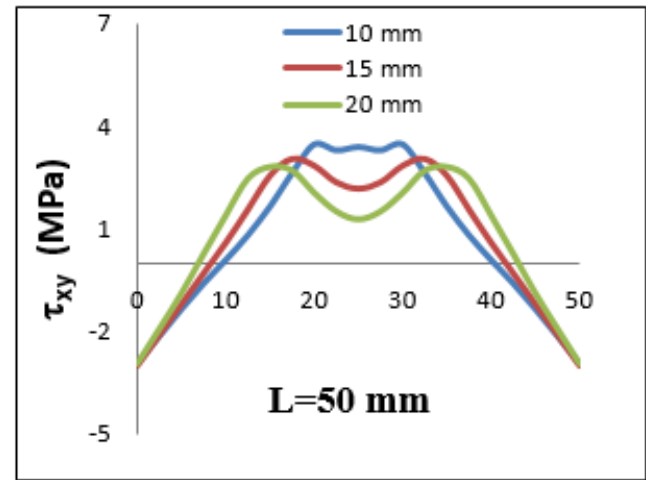

(a)

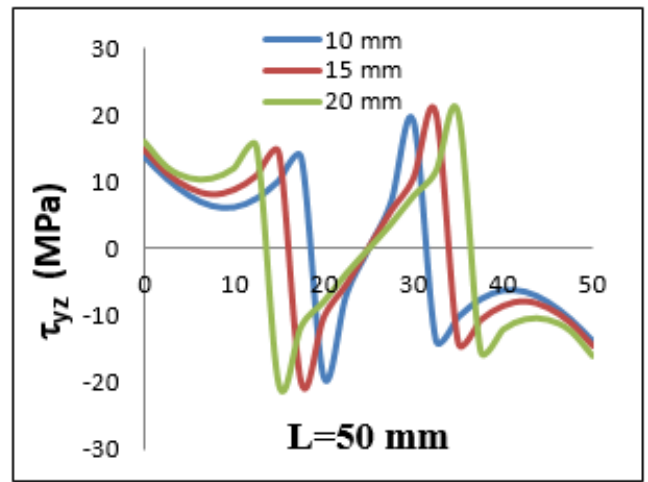

(b)

Şekil 11. $5 \mathrm{~mm}$ parça, $0.8 \mathrm{~mm}$ kapak kalınlığına ve $50 \mathrm{~mm}$ bindirme uzunluğuna sahip çift takviyeli bağlantının A-B hattı boyunca farklı ara parça boyları için kayma gerilme dağılımları a) $\tau_{x y}$, b) $\tau_{y z}$ 


\subsection{Kapak kalınlığına bağlı olarak gerilme dağılımı sonuçları}

Kapak kalınlığının artması ile ara parçalı çift takviyeli yapıştırma bağlantısında meydana gelen normal, eşdeğer ve kayma gerilme maksimum değerlerinin az da olsa azaldığı görülmektedir. eşdeğer gerilme değerlerinin ise kapak uçlarında arttığı ara parça uçlarında ise azaldığı görülmektedir(Şekil 12,13).

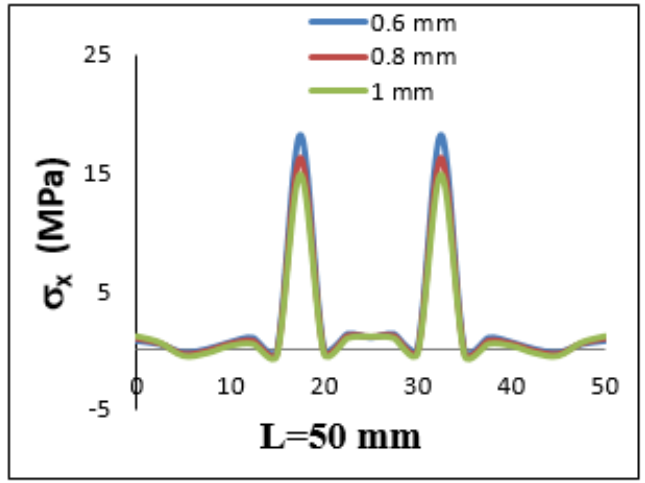

(a)

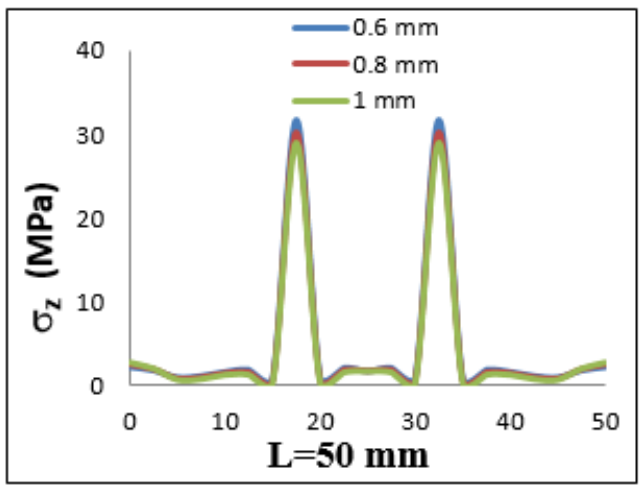

(c)

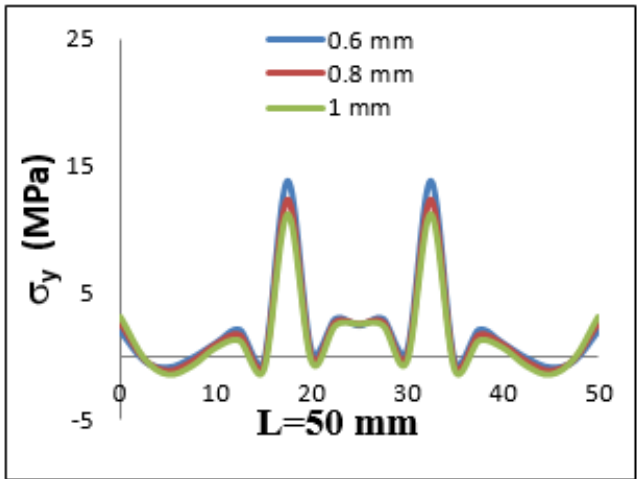

(b)

(b)

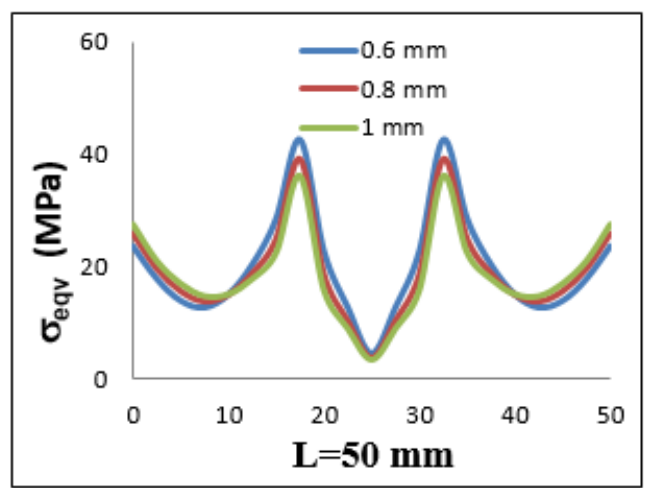

(d)

Şekil 12. $5 \mathrm{~mm}$ parça kalınlığına, $15 \mathrm{~mm}$ ara parça boyuna ve $50 \mathrm{~mm}$ bindirme uzunluğuna sahip çift takviyeli bağlantının A-B hattı boyunca farklı kapak kalınlıkları için normal ve eşdeğer gerilme dağılımları a) $\sigma_{x}$, b) $\sigma_{y}$, c) $\sigma_{z}$, d) $\sigma_{\text {eqv }}$

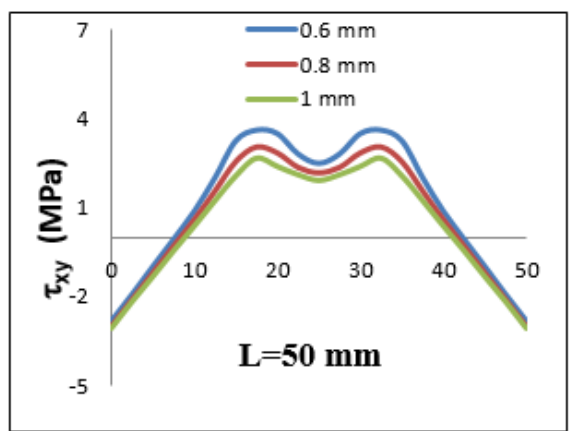

(a)

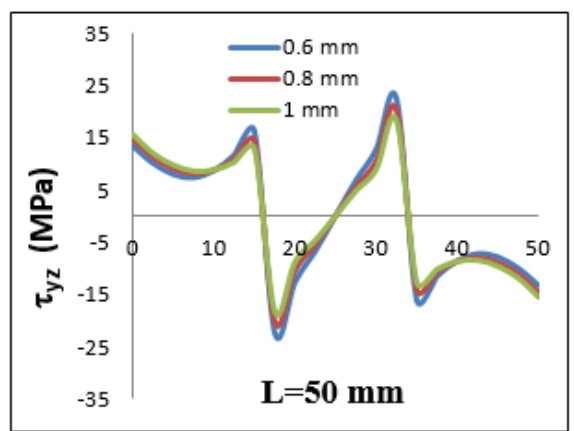

(b)

Şekil 13. $5 \mathrm{~mm}$ parça kalınlığına, $15 \mathrm{~mm}$ ara parça boyuna ve $50 \mathrm{~mm}$ bindirme uzunluğuna sahip çift takviyeli bağlantının A-B hattı boyunca farklı kapak kalınlıkları için kayma gerilme dağılımları a) $\tau_{\mathrm{xy}}$, b) $\tau_{\mathrm{yz}}$ 


\subsection{Parça kalınlığına bağlı olarak gerilme dağılımı sonuçları}

Farklı parça kalınlıkları için, $15 \mathrm{~mm}$ ara parça boyu, $0.8 \mathrm{~mm}$ kapak kalınlığına ve $50 \mathrm{~mm}$ bindirme uzunluğuna sahip çift takviyeli bağlantının A-B hattı boyunca normal, von-Mises eşdeğer ve kayma gerilme dağılımları sırasıyla şekil 12 ve 13 'da verilmiştir. parça kalınlığının $\sigma$ gerilme dağılımları üzerinde etkisi görülmemektedir.

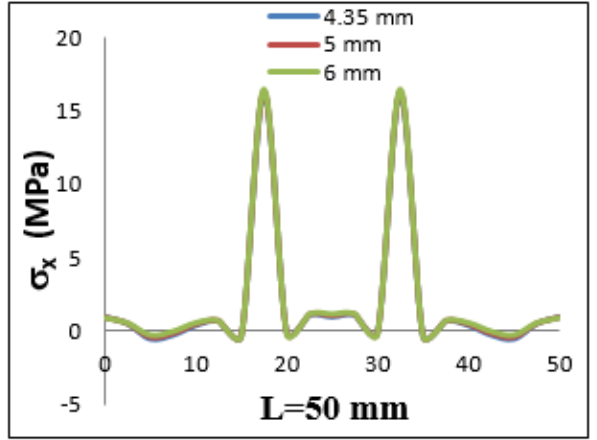

(a)

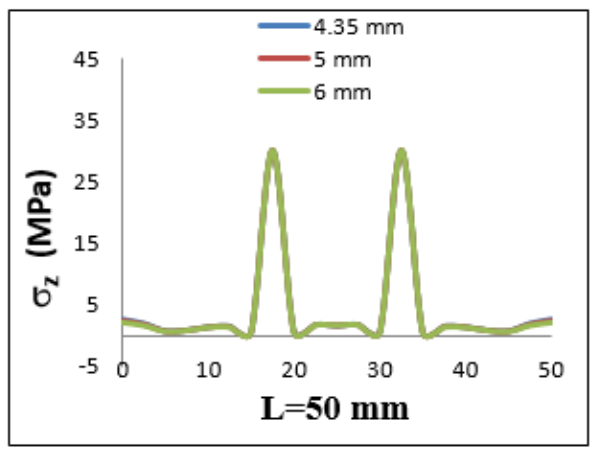

(c)

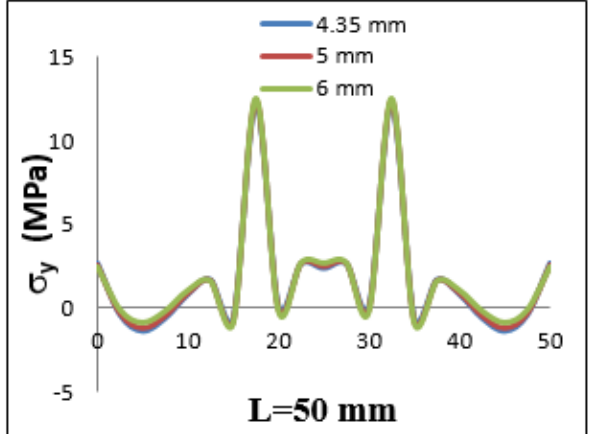

(b)

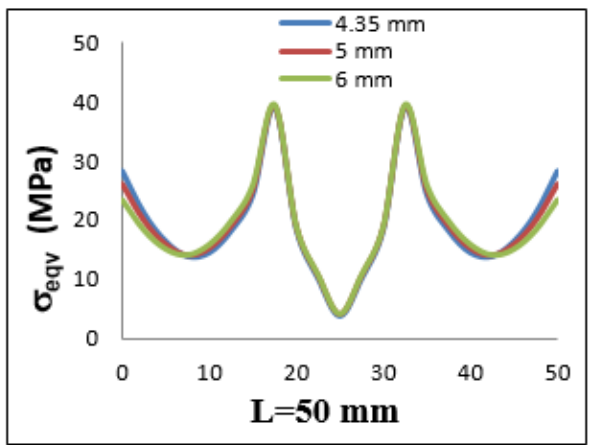

(d)

Şekil 14. $0.8 \mathrm{~mm}$ kapak kalınlığına, $15 \mathrm{~mm}$ ara parça boyuna ve $50 \mathrm{~mm}$ bindirme uzunluğuna sahip çift takviyeli bağlantının A-B hattı boyunca farklı parça kalınlıkları için normal ve eşdeğer gerilme dağılımları a) $\sigma_{x}$, b) $\sigma_{y}$, c) $\sigma_{z}$

d) $\sigma_{\text {eqv }}$ gerilme dağılımları

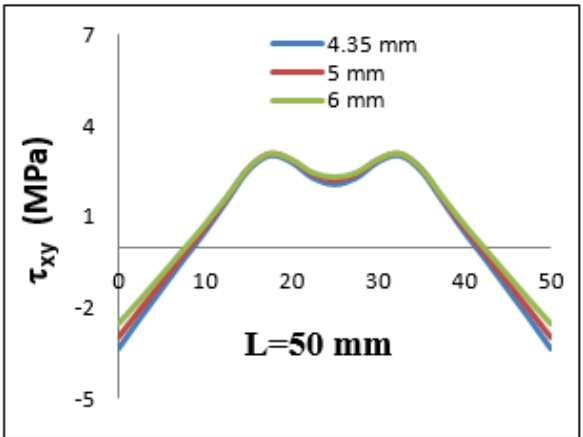

(a)

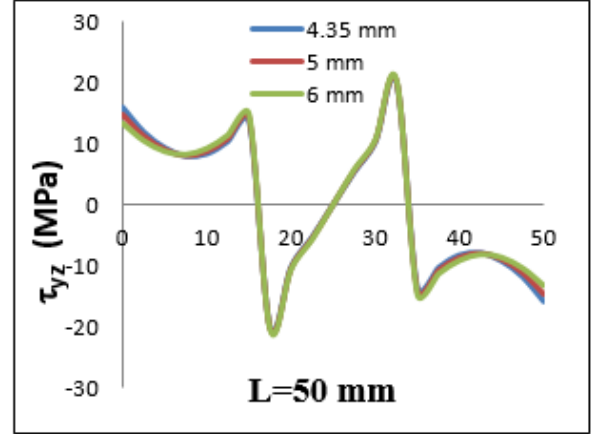

(b)

Şekil 15. $0.8 \mathrm{~mm}$ kapak kalınlığına, $15 \mathrm{~mm}$ ara parça boyuna ve $50 \mathrm{~mm}$ bindirme uzunluğuna sahip çift takviyeli bağlantının A-B hattı boyunca farklı parça kalınlıkları için kayma gerilme dağılımları a) $\tau_{\mathrm{xy}}$, b) $\tau_{\mathrm{yz}}$ gerilme dağılımları 


\section{SONUÇLAR}

Çeşitli kazalar sonucu hasara uğramış bölgelerin tamiratında hasarlı olan bölge kesilip çıkartılmakta ve kesilen bölgeye yama yapılarak onarımına gidilmektedir. $\mathrm{Bu}$ çalışmada iki yama arasındaki boş olan bölgeye çıkarılan parça boyutunca bir ara parça ilave etmek suretiyle tamirine gidilmiştir. Aynı bindirme uzunluğundaki kapaklarla farklı boylarda ara boşluklar oluşturulmuş ve bu ara boşluklar belirlenen ebattaki parçalar yapıştırılıp, kapak kalınlığının, bindirme uzunluğunun, parça kalınlığının ve ara parça boyunun mukavemet üzerindeki etkileri incelenmiştir. $\mathrm{Bu}$ inceleme sonucunda;

1. Parça kalınlığındaki artışın hasar yükünü arttırdı ̆̆1,

2. Bindirme uzunluğu arttıkça hasar yükünün arttı̆̆1,

3. Kapak (yama) kalınlığı arttıkça hasar yükünün azaldığ 1 ,

4. Ara parça boyundaki artışın hasar yükünü azalttığ 1 görülmüştür.

\section{KAYNAKLAR}

[1]. da Silva, L. F. M., Marques, E. A. S. Joint Strength Optimization of Adhesively Bonded Patches, J. Adhesion 84, 915-934, 2008.

[2]. Temiz, S., 2006. Application of bi-adhesive in double-strap joints subjected to bending moment. J. Adhesion Sci. Technol. 20, 1547-1560, 2003.

[3]. Pires, I., Quintino, L., Durodola, J. F., and Beevers, A., Int. J. Adhes. Adhes. 23, 215-223.

[4]. Fawzia S, Al-Mahaidi R, Zhao XL, Experimental and finite element analysis of a double strap joint between steel plates and normal modulus CFRP, Composite Structures, 75, 156-162, 2006.

[5]. Çitil, Ş., Temiz, Ş., Altun, H., Özel, A., "Determination of Mechanical Properties of Double-Strap Adhesive Joint with an Embedded Patch", J. Adhesion Sci. Technol., 25(18), 2555 2567, 2011.

[6]. Aydın, M.D., Temiz, Ş., Özel, A., Yapısal Yapıştırıcıların Mekanik Özelliklerinin Belirlendiği Deneysel Yöntemler. Mühendis ve Makine Cilt 45, Sayı 536, 2003 